\title{
Municipal solid waste (MSW) - competitive raw materials for combustible materials obtaining
}

https://doi.org/10.21698/rjeec.2020.221

\author{
Proceedings Paper
}

\section{AGNES SERBANESCU*, MONA BARBU, IONUT CRISTEA, LIDIA KIM, GINA ALINA CATRINA, GEORGIANA CERNICA, ILEANA NICOLESCU}

\begin{abstract}
National Research and Development Institute for Industrial Ecology - ECOIND, 71-73 Drumul Podul Dambovitei, 060652, Bucharest, Romania

*Corresponding author (e-mail): agnes.serbanescu@incdecoind.ro
\end{abstract}

\begin{abstract}
Waste-to-energy projects can be classified as a complementary technology for energy recovery from nonrecyclable municipal waste fractions and should therefore not compete with measures to reduce, reuse, and recycle materials. The article presents the characterization of some treated municipal solid wastes as competitive raw materials for combustible materials obtaining. Samples with lignocellulosic and polymeric composition were analyzed, namely 3 samples of SRFs (solid recovered fuels) used as secondary raw material in cement plants, SRF1, SRF2, SRF3; a sample of RDF, consisting of household waste; a sample of fluff (a homogeneous mixture of non-hazardous waste - selected, mechanically treated and dried) used as a secondary raw material in cement plants; 4 samples of municipal solid waste, fractions smaller than 100 mm, after a bio-drying process, with composition: paper and cardboard (70-80\%), wood (6-15\%), plastic (6$10 \%)$, glass and metal (3-14\%), MBU1, MBU2, MBU3, MBU4. The waste samples were characterized in terms of technical and elementary characteristics and the ash (obtained by the sample incineration) behavior in the combustion process. The mineral matter was investigated by the X-ray fluorescence analytical technique using the Rigaku CG X-ray Spectrofluorimeter. The analysis of the indices used for the slagging and deposit formation risks evaluation shows that the analyzed samples present an obvious risk of melt formation and deposits, due to a high content of base oxides and silicon oxide.
\end{abstract}

Keywords: ash, energy, fouling index, $M S W$, slagging index

\section{INTRODUCTION}

Waste-to-energy recovery in the EU comes to support the achievement of the objectives of the Circular Economy Action Plan [1]. The development of municipal waste management systems must follow the waste hierarchy, reduction of waste quantities, followed by materials reusing, and recycling. Waste energy projects can be classified as a complementary technology for energy recovery from municipal solid waste fractions that are not recyclable and therefore should not compete with measures to reduce, reuse, and recycle materials.

Waste treatment technologies for energy recovery in the form of heat, electricity or alternative fuels are of various complexities. These may include the production of cooking gas in household organic waste digesters, the collection of methane gas from landfills, the combustion of waste in incineration plants, the co-combustion of waste-derived fuel (RDF) in cement plants or combustion plants.

Waste treatment technologies require knowledge of waste characteristics. They are based on an efficient municipal waste management system. Only municipalities that can manage an efficient waste collection and transport system with safe final disposal will have the capacity to manage waste treatment systems to obtain energy successfully. These systems also require significant financial resources for operation and maintenance [2].

Obtaining energy from specific non-recyclable waste streams could be a viable alternative to managing increasing amounts of waste in the coming years if environmental standards are met and social issues are taken into account. Addressing the issue of using waste for energy production means reaching a new level of complexity in an already challenging situation of waste management. However, technologies for obtaining energy from waste can improve their management in cities, but its application is complex and must take into account, among others, the following specific aspects [2]:

- the heating value, parameter influenced by the moisture content and by the content of the inert 
material from waste (soil, ash, construction, and demolition waste);

- substantial changes in the composition of waste depending on the season;

- the limited practice of segregation of waste at source;

- lack of knowledge about the operation and maintenance of waste energy installations;

- high investment and operating costs, which cannot be recovered through the existing commissions on waste and the additional income generated from energy sales.

The municipal solid waste incinerator is designed to treat typical mixed and largely untreated household waste and certain industrial and commercial waste. A key parameter is their energy content, the so-called lower heating value. To ensure the autothermal combustion of waste, the lower heating value must not be less than $7 \mathrm{MJ} / \mathrm{kg}$ on average during a year. The lower heating value of unsorted household waste is usually below this threshold, due to a dominant organic content with high humidity

\section{MATERIALS AND METHODS}

The experimental study was performed on samples of mixed municipal waste, resulting from different processing stages, namely:

- 3 samples of SRFs (solid recovered fuels) used as a secondary raw material in cement plants, SRF1, SRF2, SRF3;

- a sample of RDF (refused derived fuel), consisting of household waste;

- a fluff sample (a homogeneous mixture of

\section{Equipment and methods applied}

The samples were characterized using standardized methods. Gravimetric methods were used to determine the moisture and ash content [3, 4]. Moisture and ash content are the basic parameters for the combustion process. The ash content represents the amount of inert material resulting from the combustion process. Of great importance is the behavior of the ash resulting during the combustion process, its tendency to form melts and deposits.

The higher heating value was determined using the PARR 6200 bomb calorimeter [5], and the lower heating value, one of the basic parameters for evaluating a fuel, was calculated using the higher heating value and hydrogen content. and a significant level of inert waste fractions, such as soil or sand.

The waste for incineration must meet certain basic requirements. The use of refused derived fuels in power plants and industrial furnaces requires a thorough understanding of their properties which include physical-chemical and energetic characterization, assessment of their behavior in combustion processes, assessment of emissions, impact on the installation, waste, etc.

The article presents the physical-chemical and energetic characterization and the combustion behavior of some municipal solid wastes resulted from different processing stages, as competitive raw materials for combustible materials obtaining.

The article through its results contributes to obtaining new data on the recovery of nonrecyclable waste to obtain energy. These will lead to the development of the scientific field approached.

non-hazardous waste - selected, mechanically treated and dried) used as secondary raw material at cement plants;

- 4 municipal waste samples, fractions smaller than $100 \mathrm{~mm}$, after a bio-drying process, with composition: paper and cardboard (70-80\%), wood $(6-15 \%)$, plastic (6-10\%), glass and metal (3-14\%), MBU1, MBU2, MBU3, MBU4.

The elemental analysis, respectively the determination of the carbon, nitrogen, and hydrogen content was performed by a chromatographic method, using the Thermo Scientific Flash EA 1112 elemental analyzer based on the Flash Dynamic Combustion method [6]. During the determination, there is complete combustion of the sample in a reactor at high temperature, in oxygen stream, and in the presence of a catalyst, followed by a precise determination of the elemental gases produced $\left(\mathrm{N}_{2}, \mathrm{CO}_{2}, \mathrm{H}_{2} \mathrm{O}\right.$, and $\left.\mathrm{SO}_{2}\right)$, using a thermal conductivity detector. The combustion temperature of the sample was $950^{\circ} \mathrm{C}$. The sulphur content was determined using a 
spectrophotometric method, and the chlorine content using a volumetric method [7].

The oxide composition of the analysed sample ashes (combusted at $815^{\circ} \mathrm{C}$ ), was determined by the X-ray fluorescence analytical technique, using the Rigaku CG X-ray Spectrofluorimeter [8].

\section{RESULTS AND DISCUSSION}

\section{Technical and elementary characteristics}

The technical and elementary characteristics of the studied samples (Table 1 and Table 2) are presented at the as-received state (ar) of the waste and on a dry basis $(\mathrm{db})$.

Table 1. Technical and elementary characteristics for the analyzed sample, as received state

\begin{tabular}{|c|c|c|c|c|c|c|c|c|c|}
\hline $\begin{array}{c}\text { Sample / } \\
\text { Indices }\end{array}$ & $\begin{array}{c}\mathrm{W}_{\mathrm{t}} \\
\text { (wt.\%) }\end{array}$ & $\begin{array}{c}\mathrm{A} \\
\text { (wt. } \% \text { ar) } \\
\end{array}$ & $\begin{array}{c}\text { LHV } \\
\mathrm{MJ} / \mathrm{kg} \text { ar }\end{array}$ & $\begin{array}{c}\mathrm{C} \\
\text { (wt.\% ar) }\end{array}$ & $\begin{array}{c}\mathrm{H} \\
\text { (wt.\% ar) }\end{array}$ & $\begin{array}{c}\mathrm{N} \\
\text { (wt.\% ar) }\end{array}$ & $\begin{array}{c}\mathrm{S} \\
\text { (wt. } \% \text { ar) }\end{array}$ & $\begin{array}{c}\mathrm{Cl} \\
\text { (wt.\% ar) }\end{array}$ & $\begin{array}{c}\mathrm{A}+\mathrm{W}_{\mathrm{t}} \\
\text { (wt.\% ar) }\end{array}$ \\
\hline \multicolumn{10}{|c|}{ SRF } \\
\hline SRF1 & 34.2 & 8.70 & 12.71 & 33.47 & 4.14 & 2.07 & 0.48 & 0.14 & 42.90 \\
\hline SRF2 & 39.3 & 11.98 & 10.79 & 26.68 & 3.11 & 0.99 & 0.24 & 0.14 & 51.28 \\
\hline SRF3 & 30.0 & 8.13 & 13.54 & 35.38 & 4.95 & 0.89 & 0.46 & 0.56 & 38.13 \\
\hline \multicolumn{10}{|c|}{ RDF } \\
\hline RDF & 35.2 & 17.79 & 12.85 & 33.72 & 3.32 & 0.47 & 0.12 & 0.68 & 52.99 \\
\hline \multicolumn{10}{|c|}{ FLUFF } \\
\hline FLUFF & 5.5 & 10.33 & 19.36 & 47.62 & 4.76 & 2.15 & 0.15 & 0.42 & 15.83 \\
\hline \multicolumn{10}{|c|}{$\mathrm{MBU}$} \\
\hline MBU1 & 40.2 & 7.69 & 9.42 & 25.95 & 3.38 & 1.66 & 0.13 & 0.14 & 47.89 \\
\hline MBU2 & 45.1 & 16.59 & 6.31 & 20.10 & 2.28 & 0.61 & 0.26 & 0.29 & 61.69 \\
\hline MBU3 & 53.2 & 15.33 & 4.01 & 14.75 & 1.85 & 0.52 & 0.23 & 0.24 & 68.53 \\
\hline MBU4 & 36.4 & 25.44 & 5.90 & 17.32 & 2.22 & 0.63 & 0.27 & 0.32 & 61.84 \\
\hline
\end{tabular}

ar - as received; LHV-low heating value

Table 2. Technical and elementary characteristics for the analyzed sample, dry basis

\begin{tabular}{|c|c|c|c|c|c|c|c|}
\hline $\begin{array}{l}\text { Sample / } \\
\text { Indices }\end{array}$ & $\begin{array}{c}\text { A } \\
\text { (wt.\% db) }\end{array}$ & $\begin{array}{c}\text { LHV } \\
(\mathrm{MJ} / \mathrm{kg} \mathrm{db})\end{array}$ & $\begin{array}{c}\mathrm{C} \\
\text { (wt.\% db) }\end{array}$ & $\begin{array}{c}\mathrm{H} \\
\text { (wt.\% db) }\end{array}$ & $\begin{array}{c}\mathrm{N} \\
\text { (wt.\% db) }\end{array}$ & $\begin{array}{c}\mathrm{S} \\
\text { (wt.\% db) }\end{array}$ & $\begin{array}{c}\mathrm{Cl} \\
\text { (wt.\% db) }\end{array}$ \\
\hline \multicolumn{8}{|c|}{ SRF } \\
\hline SRF1 & 13.23 & 20.52 & 50.87 & 6.29 & 3.14 & 0.73 & 0.21 \\
\hline SRF2 & 19.75 & 19.28 & 43.97 & 5.13 & 1.63 & 0.40 & 0.24 \\
\hline SRF3 & 12.01 & 21.10 & 52.26 & 7.31 & 1,31 & 0.67 & 0.38 \\
\hline \multicolumn{8}{|c|}{ RDF } \\
\hline $\mathrm{RDF}$ & 27.43 & 21.06 & 52.00 & 5.13 & 0.72 & 0.19 & 1.05 \\
\hline \multicolumn{8}{|c|}{ FLUFF } \\
\hline FLUFF & 10.93 & 20,62 & 50.39 & 5.04 & 2.28 & 0.16 & 0.44 \\
\hline \multicolumn{8}{|c|}{ MBU } \\
\hline MBU1 & 12.87 & 17.30 & 43.41 & 5.65 & 2.77 & 0.31 & 0.36 \\
\hline MBU2 & 30.21 & 13.38 & 36.62 & 4.15 & 1.11 & 0.47 & 0.53 \\
\hline MBU3 & 32.76 & 11.17 & 31.51 & 3.96 & 1.11 & 0.49 & 0.52 \\
\hline MBU4 & 40.41 & 10.73 & 27.50 & 3.52 & 0.99 & 0.42 & 0.50 \\
\hline
\end{tabular}

db-dry basis; LHV-low heating value

Moisture content and heating value are the main economic parameters for waste characterization. Both of them negatively influence the heating value. For the analyzed SRF and RDF samples the moisture content was between 30.0 and $39.3 \%$. The municipal solid waste samples (MBU) had a moisture content between 36.4 and $45.1 \%$. The lowest moisture content was found in the FLUFF sample respective $5.5 \%$.
The lower heating value is the most important economic parameter. The analyzed SRF, RDF, and FLUFF samples had lower heating value expressed at a dry basis between 20.52 and $21.10 \mathrm{MJ} / \mathrm{kg}$. For the as received waste, the lower heating value was between 10.79 and $13.57 \mathrm{MJ} / \mathrm{kg}$. For the municipal waste samples (MBU) the lower heating value on a dry basis was between $10.73 \mathrm{MJ} / \mathrm{kg}$ and $13.38 \mathrm{MJ} / \mathrm{kg}$, 
excepting the MBU1 sample, which lowers heating value was $17.30 \mathrm{MJ} / \mathrm{kg}$. MBU1 sample had the lowest ash content. The municipal waste samples MBU2 $\div$ MBU4 had at as received basis lower heating value between 4.01 and $6.31 \mathrm{MJ} / \mathrm{kg}$.

Data from the literature show that the minimum lower heating value for incineration must be 6 $\mathrm{MJ} / \mathrm{kg}$ [9]. The mentioned samples presented high content of inert matter. The MBU1 sample had a lower heating value at a received basis of $9.42 \mathrm{MJ} / \mathrm{kg}$, a value that is above the minimum required value of $7 \mathrm{MJ} / \mathrm{kg}$ for self-sustaining combustion.

The ash and chlorine content is technical parameters that influence performance during the combustion process. The ash content generates problems of melting and sintering at high temperatures.

The ash content was $8.13 \%$ and $11.98 \%$ for the SRF sample, $17.79 \%$ for the RDF sample, and $10.33 \%$ for the fluff sample. The municipal waste samples (MBU) had an ash content between $7.69 \%$ and $25.44 \%$. The highest ash content value expressed on a dry basis for the analyzed samples was found for the municipal waste samples (MBU), due to the high content of the inert component (soil) in their composition.

Chlorine in waste-derived fuels originates mainly from chlorinated plastics (PVC), food residues or flame retardants. Chlorine is the main initiator of slagging, fouling, and corrosion in waste combustion as it lowers the melting point of ash forming matter and reacts chemically with the heat transfer surface steels [10].

Chlorine in waste is an element that facilitates the reaction between potassium and silicon, leading to the formation of glass silicon melts and slag melts at an operating temperature of $800-900^{\circ}$ C. Samples with a chlorine content lower than $0.2 \%$ (SRF1, SRF2, MBU1), show a low tendency to form melts taking into account this indicator, those with a chlorine content between 0.2-0.3\% (MBU2, MBU3, MBU4) shows a medium melting tendency, for a chlorine content between $0.3-0.5 \%$, fluff sample, the melting tendency is high, and for a chlorine content higher than $0.5 \%$ (SRF3 and RDF) the melt formation tendency is very high considering the chlorine indicator [11].

The environmental parameters are represented by the characteristics that determine the level of emissions, namely the nitrogen and sulphur content. The municipal waste samples MBU2 $\div$ MBU4 had an average nitrogen content, between $0.52 \%-0.61 \%$, as well as the RDF sample, except the MBU1 sample, which had a high nitrogen content of $1.66 \%$. SRF samples had an average nitrogen content of approx. $0.9 \%$, except for the SRF1 sample, which had a high nitrogen content of $2.07 \%$, as the fluff sample did.

The sulphur content of the analyzed samples was low between $0.12 \%-0.48 \%$, at an asreceived state.

\section{Ash behavior during the combustion process (slag and deposits formation tendency)}

During the combustion of solid waste, volatile organometallic compounds are first released followed by devolatilization and char particle formation. Partial alkali and alkali-earth elements (e.g. K, $\mathrm{Na}$, and $\mathrm{Ca}$ ) and volatile trace elements (e.g., $\mathrm{Hg}$, As, and Se) diffused out of the char. As the gas temperature decreases, the volatile components nucleate and condense to form submicron-sized particle. Some volatile material condenses on residual fly ash [12].

On the heat transfer surfaces in the combustion, installations are defined two types of ash deposits depending on the involved formation mechanism, namely in the form of melts (slag) and in the form of ash deposits (agglomerations). Slagging is the formation of molten or partially molten deposits on the firebox walls or on convection surfaces exposed to radiant heat.

Ash agglomeration deposits are formed on thermal convection surfaces, such as superheaters and heat recuperators. The primary mechanism involves the condensation of previously volatilized compounds. As a result, the inner deposition layer is often composed of condensed alkaline salts, which provide a sticky surface for trapping other non-stick particles.

Melts are formed in situations where the particles of melted or softened ash are not cooled until the solid-state is obtained when they reach the heat exchange surface. Due to the temperatures in the firebox, the ash is in a semi- 
melted state, being able to stick to the relatively colder walls. Most types of ash tend to solidify due to the lower temperature at the transfer surface, and the particles return to the gas stream. However, if the firebox is too small, the gas outlet temperature is too high, or the melting point of the ash is relatively low, the melted ash may not have enough time to solidify when it reaches the heat exchange surfaces, causing accumulation of deposits leading to slag formation.

Depending on the physical characteristics of the deposits, they can be removed by the gas stream. However, the base deposits cannot be removed and remain attached to the piping, allowing subsequent deposits to accumulate much faster.

The chemical and mineralogical composition of the ash has significant effects on its properties during the combustion processes.

In the combustion process, in the firebox, take place a series of physical changes of the ash. As the temperature rises, the ash particles soften until they completely melt. Fuels with low ash melting temperatures increase the risk of slag formation. The melting temperature of the ashes varies depending on several factors, the most important of which is the nature of the combustible waste used as raw material.

Slag formation increases the heat transfer resistance leading to overall efficiency decreasing. The reduced heat transfer increases the firebox gas temperature. As the temperature rises, the ash particles soften until they are completely melted. The major ash-forming elements ( $\mathrm{Si}, \mathrm{Al}, \mathrm{Ca}, \mathrm{Fe}, \mathrm{Mg}, \mathrm{P}, \mathrm{K}, \mathrm{Na}$, and $\mathrm{Ti}$ ) are responsible for ash behavior.

The evaluation of the slag and deposit formation tendency for the analyzed samples was performed based on the oxide composition of the sample ashes resulting in calcination at $815^{\circ} \mathrm{C}$. The oxide composition of the ashes is presented in Table 3.

Table 3. Ash composition expressed as oxides, wt. \%

\begin{tabular}{|c|c|c|c|c|c|c|c|c|c|c|}
\hline Sample Ash / Oxides & $\mathrm{SiO}_{2}$ & $\mathrm{Al}_{2} \mathrm{O}_{3}$ & $\mathrm{CaO}$ & $\mathrm{MgO}$ & $\mathrm{Na}_{2} \mathrm{O}$ & $\mathrm{K}_{2} \mathrm{O}$ & $\mathrm{Fe}_{2} \mathrm{O}_{3}$ & $\mathrm{MnO}$ & $\mathrm{TiO}_{2}$ & $\mathrm{P}_{2} \mathrm{O}_{5}$ \\
\hline \multicolumn{11}{|c|}{ SRF } \\
\hline SRF1 & 26.28 & 8.14 & 25.79 & 6.10 & 8.63 & 4.85 & 3.31 & 0.17 & 2.39 & 7.58 \\
\hline SRF2 & 32.06 & 10.39 & 29.99 & 3.24 & 7.18 & 2.13 & 4.00 & 0.12 & 1.96 & 2.04 \\
\hline SRF3 & 27.08 & 10.62 & 35.43 & 3.17 & 6.85 & 1.72 & 3.94 & 0.16 & 2.60 & 1.43 \\
\hline \multicolumn{11}{|c|}{ RDF } \\
\hline $\mathrm{RDF}$ & 27.70 & 13.40 & 29.17 & 2.15 & 5.09 & 1.33 & 13.44 & 0.14 & 2.33 & 1.99 \\
\hline \multicolumn{11}{|c|}{ FLUF } \\
\hline FLUFF & 14.68 & 8.94 & 38.77 & 4.86 & 4.92 & 0.73 & 12.09 & 0.13 & 10.48 & 0.95 \\
\hline \multicolumn{11}{|c|}{ MBU } \\
\hline MBU1 & 26.89 & 8.80 & 36.90 & 3.72 & 7.79 & 2.22 & 2.23 & 0.16 & 1.20 & 3.35 \\
\hline MBU2 & 32.58 & 9.67 & 30.15 & 2.96 & 7.12 & 2.05 & 4.05 & 0.15 & 1.27 & 2.31 \\
\hline MBU3 & 36.06 & 7.95 & 29.66 & 3.50 & 7.76 & 2.48 & 2.79 & 0.14 & 0.70 & 3.11 \\
\hline MBU4 & 37.79 & 10.50 & 24.34 & 3.02 & 7.76 & 2.39 & 5.16 & 0.17 & 0.67 & 2.21 \\
\hline
\end{tabular}

The main components of the ash are the following oxides: $\mathrm{SiO}_{2}, \mathrm{CaO}, \mathrm{Al}_{2} \mathrm{O}_{3}, \mathrm{Na}_{2} \mathrm{O}$, $\mathrm{MgO}, \mathrm{Fe}_{2} \mathrm{O}_{3}, \mathrm{~K}_{2} \mathrm{O}$, TiO2, $\mathrm{P}_{2} \mathrm{O}_{5}$. The analyzed samples had considerable calcium content. The potassium content was relatively low, while the sodium content was in a medium proportion. The presence of even relatively low concentrations of sodium and potassium contributes to the formation of eutectics that can produce the phenomenon of slag and deposits. The process of ash melting is complex and can involve sintering, shrinkage, and swelling. If the ash melting temperature is too low, it will lead to slagging, fouling, and corrosion in boilers, reducing the conversion efficiency.
Based on the temperature effects on the ash, there are four characteristic temperatures [13]: - the deformation temperature (DT) at which the test piece presents the first signs of rounding, due to melting. This temperature corresponds to the temperature level in an operating firebox in which ash particles get a slight tendency to stick, being able to deposit on heat transfer surfaces. When the ash particles transported in the flue gas have the temperature below the ash deformation temperature, the deposits from the boiler pipes tend to accumulate in the form of a "dry" product. As a consequence, the combustion plants must be designed in such a way that the firebox flue gases leaving 
temperature to be $50^{\circ} \mathrm{C}$ below the deformation temperature (DT) to avoid the particles sintering and the slag risk.

- The sphere temperature (ST) - in the case of pyramidal and truncated-cone test pieces, the temperature at which the height of the test pieces is equal to the width of the base, and in the case of cubical or cylindrical test pieces, the temperature at which the edges of the test pieces become completely round with the height remains unchanged. At this temperature, the ash tends to stick to the heat transfer surfaces.

- The hemisphere temperature (HT) - the temperature at which the test piece forms approximately a hemisphere (i.e. the height becomes equal to half the base diameter). At this temperature, the ash particles tend to aggregate together and stick to the heat transfer surfaces.

- The flow temperature (FT) - the temperature at which the ash melt is spread out over the supporting tile in a layer, the height of which is one-third of the test piece at the hemisphere temperature. At the flow temperature, ash deposits tend to drain from the surfaces on which they were deposited [14].

For the design and the operation of combustion, plants are important to know the ash characteristic temperature. In the case of layer combustion, the exceeding of the deformation temperature can lead to the formation of slag on the grate (which blocks the entry of air through the fuel layer). In spray combustion, the deformation temperature exceeding in the firebox makes that the particles, in plastic or even liquid state, to deposit on the external surface of the pipes (superheater), forming an increasingly thick layer. The particles that deposit on the firebox walls also have a harmful action, forming deposits that attack the refractory masonry. To avoid these shortcomings, it is recommended that the gas temperature at the exit of the firebox to be lower than the ash deformation temperature or the application of constructive methods.

According to the exerting influence on the characteristic temperatures, the oxides in the ash are divided into two groups: a group of acid oxides that raises the temperature of the characteristic temperatures: $\mathrm{SiO}_{2}, \mathrm{Al}_{2} \mathrm{O}_{3}$, and $\mathrm{TiO}_{2}$; a group of basic oxides that lowers the temperature of the characteristic temperatures: $\mathrm{FeO}, \mathrm{Fe}_{2} \mathrm{O}_{3}, \mathrm{CaO}, \mathrm{MgO}, \mathrm{Na}_{2} \mathrm{O}, \mathrm{K}_{2} \mathrm{O}$.

The ash compositions of the samples were used to calculate different slagging and fouling indices, as follows in equations 1 to 5 [15].

The sum of basic oxides was calculated from the number of basic oxides as given in Eq. (1):

$$
R_{b}=\mathrm{FeO}_{3}+\mathrm{CaO}+\mathrm{MgO}+\mathrm{Na}_{2} \mathrm{O}+\mathrm{K}_{2} \mathrm{O}+\mathrm{P}_{2} \mathrm{O}_{5}
$$

The base-to-acids ratio calculated by the following equation:

$$
R_{b / a}=\left(\mathrm{Fe}_{2} \mathrm{O}_{3}+\mathrm{MgO}+\mathrm{Na}_{2} \mathrm{O}+\mathrm{K}_{2} \mathrm{O}+\mathrm{P}_{2} \mathrm{O}_{5}\right) /\left(\mathrm{SiO}_{2}+\mathrm{Al}_{2} \mathrm{O}_{3} \mathrm{TiO}_{2}\right)
$$

The ratio of silica or viscosity index calculated by the following equation:

$$
R S:\left(\mathrm{SiO}_{2} * 100\right) /\left(\mathrm{SiO}_{2}+\mathrm{Fe}_{2} \mathrm{O}_{3}+\mathrm{CaO}+\mathrm{MgO}\right)
$$

The alkali index was calculated from the quantity of alkali oxides in the fuel per unit of

$$
A I: \frac{N a_{3} O+K_{3} O}{H H V}\left({ }^{k g} / G J\right)
$$

The fouling index was calculated by the

$$
F_{u}: R_{b / a} x\left(\mathrm{Na}_{2} \mathrm{O}+\mathrm{K}_{2} \mathrm{O}\right)
$$

The calculated indices for the analyzed samples are presented in Table 4. Fig. 1-5 show the fuel energy ( $\mathrm{kg}$ alkali/GJ) as given in Eq. (4):

following equation:

comparison between the calculated indices and the delimitation for risks induced limits. 
The silicon content is usually the predominant element in the slag composition, confirming that the melt formed from silicates is responsible for the formation of slag [15]. Silicon content is an indicator of slag formation risk. $\mathrm{A} \mathrm{SiO}_{2}$ content less than $20 \%$ implies a low tendency of slag formation, a content between $20-25 \% \mathrm{SiO}_{2}$, implies a medium risk of slag formation, while a $\mathrm{SiO}_{2}$ content higher than $25 \%$, leads to a high slag formation risk. For the analyzed samples, only the fluff sample had a $\mathrm{SiO}_{2}$ content $<20 \%$, so a low risk of slag formation due to the $\mathrm{SiO}_{2}$ content, while all other samples had a $\mathrm{SiO}_{2}$ content> of $25 \%$, so a high slag formation risk in terms of $\mathrm{SiO}_{2}$ content.

Table 4. Slagging and fouling indices for the analysed sample

\begin{tabular}{|c|c|c|c|c|c|c|}
\hline Sample / Indices & $\mathrm{Ra}$ & $\mathrm{Rb}$ & $\mathrm{R}_{\mathrm{b} / \mathrm{a}+\mathrm{P}}$ & SR & $\mathrm{F}_{\mathrm{u}}$ & AI \\
\hline \multicolumn{7}{|c|}{ SRF } \\
\hline SRF1 & 36.81 & 56.25 & 1.27 & 42.75 & 20.59 & 0.70 \\
\hline SRF2 & 44.41 & 48.58 & 1.05 & 46.27 & 10.18 & 0.52 \\
\hline SRF3 & 40.29 & 52.54 & 1.26 & 38.90 & 11.18 & 0.44 \\
\hline \multicolumn{7}{|c|}{ RDF } \\
\hline RDF & 43.43 & 53.16 & 1.17 & 38.23 & 7.86 & 0.32 \\
\hline \multicolumn{7}{|c|}{ FLUFF } \\
\hline FLUFF & 34.10 & 62.31 & 1.78 & 20.85 & 10.32 & 0.28 \\
\hline \multicolumn{7}{|c|}{ MBU } \\
\hline MBU1 & 36.90 & 56.21 & 1.40 & 38.56 & 15.25 & 0.62 \\
\hline MBU2 & 43.51 & 48.63 & 1.06 & 46.72 & 10.25 & \\
\hline MBU3 & 44.71 & 49.31 & 1.03 & 50.08 & 11.30 & 0.97 \\
\hline MBU4 & 48.96 & 44.88 & 0.88 & 53.75 & 9.31 & 1.01 \\
\hline
\end{tabular}

Basic oxides lowering the ash deformation temperature. All the analyzed samples, excepting the Fluff sample, are positioned in the range between $35-55 \%$, which places them in the low ash deformation temperature. Fig. 1 shows the basic oxide content $(\mathrm{Rb})$ for the analyzed samples.

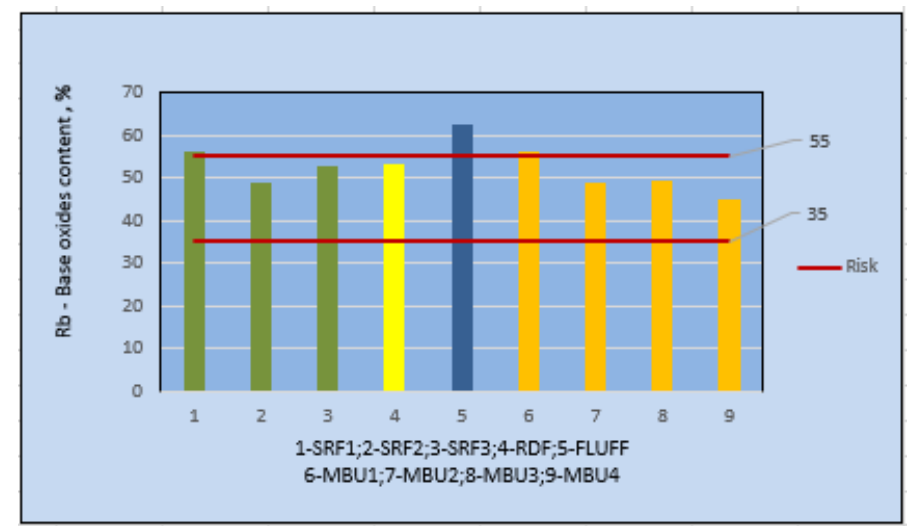

Fig. 1. The base oxides $\left(\mathrm{R}_{\mathrm{b}}\right)$ for the analyzed samples and the deformation temperature tendency

The base-to-acids ratio is the simplest indicator used to evaluate the slag and sintering tendency. The presence of $\mathrm{Fe}_{2} \mathrm{O}_{3}$ and $\mathrm{P}_{2} \mathrm{O}_{5}$, influence the sintering properties of the ash. The presence of $\mathrm{P}_{2} \mathrm{O}_{5}$ leads to a decrease of melting temperature (the melting temperature of $\mathrm{P}_{2} \mathrm{O}_{5}$ is $569^{\circ} \mathrm{C}$ ). The base-to-acids ratio $\left(\mathrm{R}_{\mathrm{b} / \mathrm{a}+\mathrm{P}}\right)$ for the analyzed samples is presented in fig. 2. For $\left(R_{b / a+P}\right)<0.15$ both characteristic temperatures, hemisphere temperature (HT) and fluidization temperature (FT) exceed $1600^{\circ} \mathrm{C}$. The lower the $\left(\mathrm{R}_{\mathrm{b} / \mathrm{a}+\mathrm{P}}\right)$ ratio, the higher the $\mathrm{HT}$ and $\mathrm{FT}$, consequently the slagging tendency decreases. For $\mathrm{R}_{\mathrm{b} / \mathrm{a}+\mathrm{P}} \sim$ 0.75 , HT and FT are below $1200^{\circ} \mathrm{C}$, resulting in a very high slag tendency [16]. For all the analyzed samples the slagging tendency is very high, the base-to-acids ratio exceeds the 0.75 value. 


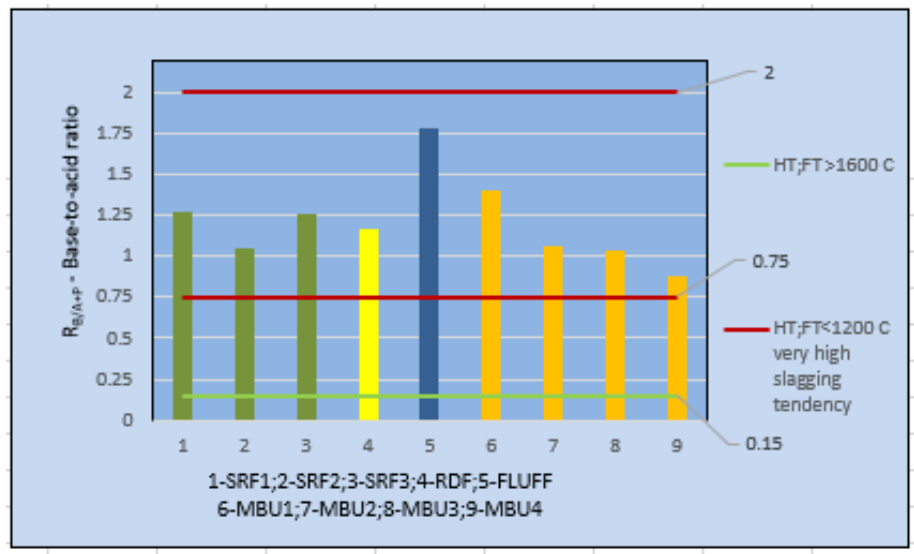

Fig. 2 The base-to-acids ratio $\left(\mathrm{R}_{\mathrm{b} / \mathrm{a}+\mathrm{p}}\right)$ for the analyzed samples and the slagging tendency

Calcium and iron content in ash in important in the predisposition for ash slagging. This can be evaluated by silica ratio or viscosity index RS. A high melt viscosity index corresponds to a reduced tendency to slag. For RS > 72 the slagging tendency is small; $72 \geq \mathrm{RS}>65$ the slagging tendency is average; $\mathrm{RS} \leq 65$ slag tendency is high [15]. The analyzed samples show a high risk of slagging do to the viscosity index (Fig. 3).

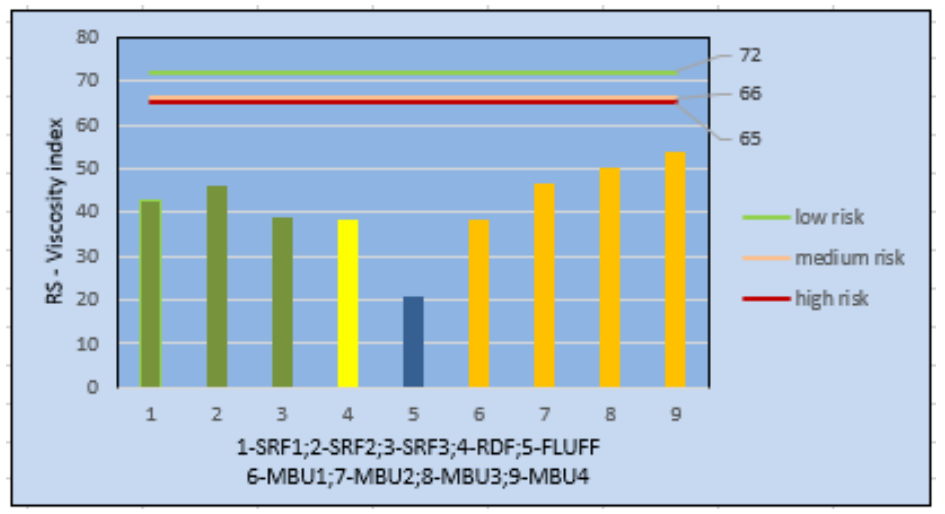

Fig. 3 The viscosity index (RS) for the analyzed samples and the slagging tendency

The alkalinity index represents the amount of alkaline oxides per unit of combustible waste $(\mathrm{kg} / \mathrm{GJ})$. When the alkalinity index is in the range of $0.17-0.34 \mathrm{~kg} / \mathrm{GJ}$, the slagging and the formation of the deposits is probable. A value higher than $0.34 \mathrm{~kg} / \mathrm{GJ}$, indicates a high probability of slagging and deposit formation. The RDF and fluff sample had a probable risk of slagging and deposit formation, while for all other samples the risk is high [15].

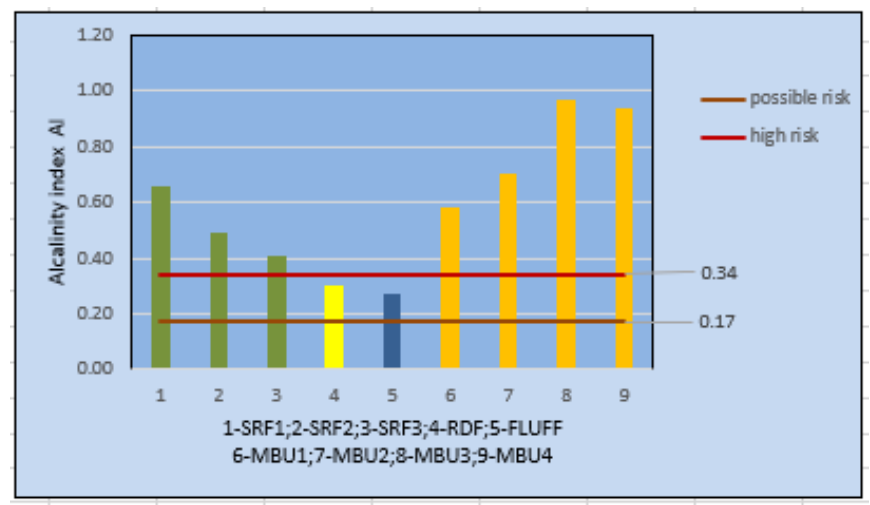

Fig. 4. The alkalinity index (AI) for the analysed samples and the slagging and deposits formation tendency

The fouling index $\mathrm{Fu}$ is based on the base-to- produces eutectics in combination with silica acids ratio and the alkali content. Alkali and consequently high tendency of fouling. The 
deposits formatted on the heat transfer surfaces, decrease the installation capacity, lead to excess fuel using, installation lifetime decreasing, and operation failure.

For $\mathrm{F}_{\mathrm{u}} \leq 0.6$, the deposits tendency of ash is low, for $0.6<\mathrm{Fu} \leq 40$ the deposits tendency of ash is high, and for $\mathrm{Fu}>40$ the tendency of agglomeration (sintering) of deposits is high. The fouling index for all the analyzed sample (Fig. 5) show a high tendency for deposits and sinter formation $(0.6<\mathrm{Fu}<40)[15]$.

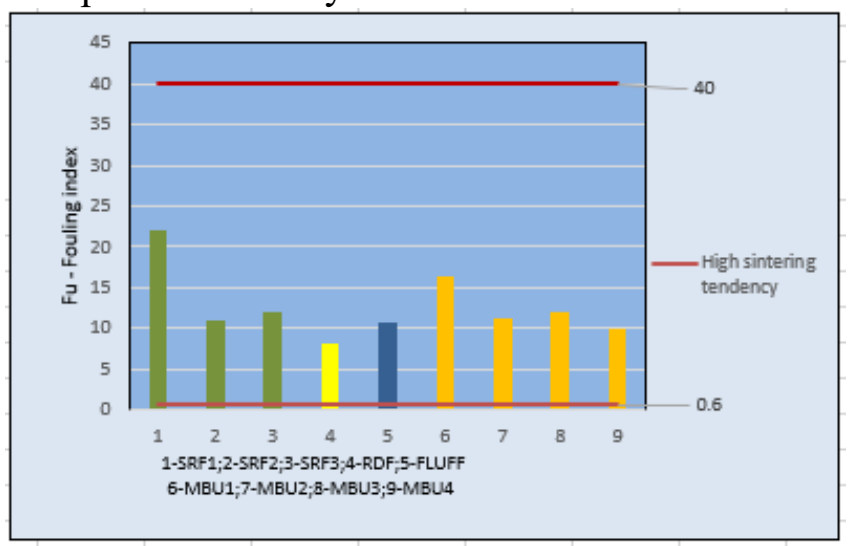

Fig. 5. The fouling index Fu for the analyzed samples and the deposits and sintering tendency

\section{CONCLUSIONS}

The paper presents the physicochemical and energetic characterization of some treated municipal solid waste samples according to their use as secondary raw materials in incineration and co-incineration processes, to three main criteria: economic, technical, and environmental.

The analyzed SRFs, RDF, and fluff samples showed a high calorific value on a dry basis (19-21 MJ/ kg), close to that of medium quality coal. The municipal waste samples (MBU) showed a relatively low calorific value due to their high ash content.

\section{ACKNOWLEDGEMENTS}

This work was carried out through the Nucleu Program (PN 190404 01) financed by the

\section{REFERENCES}

[1] European Commision, The role of waste-toenergy in the circular economy, Brussels, 26.01.2017.

[2] Waste-to-Energy Options in Municipal Solid Waste Management, A Guide for Decision Makers in Developing and Emerging Countries Waste, Deutsche Gesellschaft fur Internationale Zusammenarbeit (GIZ) $\mathrm{GmbH}$.

[3] CEN / TS 15414-2:2010, Solid recovered fuels - determination of moisture content using the oven-dry method - part 2: determination of total moisture content by a simplified method.
The samples were also evaluated in terms of ash behavior during the combustion process by using indices developed for slagging and fouling during coal combustion. The analysis of the indices shows that the waste samples present an obvious risk of melt and deposits formation.

The use of these materials as secondary raw materials in incineration and co-incineration requires a complete characterization to predict their behavior during combustion and to have data for the design of appropriate incineration or co-incineration facilities, as well as to identify their impact on the environment.

Ministry of Education and Research.

[4] EN 15403:2011, Solid recovered fuels. Determination of ash content.

[5] EN 15400:2011, Solid recovered fuels. Determination of calorific value.

[6] EN 15407:2011, Solid recovered fuels. Methods for the determination of carbon (C), hydrogen $(\mathrm{H})$ and nitrogen $(\mathrm{N})$ content.

[7] EN 14582:2017, Characterization of waste Halogen and sulfur content - Oxygen combustion in closed systems and determination methods. 
[8] EN 15309: 2007, Characterization of waste and soil. Determination of elemental composition by

$\mathrm{X}$-ray fluorescence.

[9] Municipal Solid Waste Incineration, World Bank Technical Guidance Report, 2000,

http://web.mit.edu/urbanupgrading/urbanenviro nment/resources/references/pdfs/MunicipalSWI ncin.pdf. [01.07.2020].

[10] DEL ZOTTO, L., TALLINI, A., DI SIMONE, G., MOLINAR,I G., CEDOLA, L., Energy Procedia, 81, 2015, p. 319, https://doi.org/10.1016/j.egypro.2015.12.102.

[11] VEGA-NIEVA, D., GARCIAMARAVER, A., ORTIZ, L., WIT Trans. State
Art Sci. Eng., 85, 2015, p. 137, https://doi:10.2495/978-1-84566-062-8/008.

[12] YANQING, N, HOUZHANG, T, SHIEN, H., Prog. Energy Combust. Sci., 52, 2016, p. 1.

[13] ISO 540:2008(E), Hard coal and coke. Determination of ash fusibility.

[14] ANDREI, S., Termotehnica, 1, 2011, p. 22.

[15] GARCIA-MARAVER, A., MATASANCHEZ, J., CARPIO, M., PEREZJIMENEZ, J.A., J. Energy Inst., 90, 2017, p. 214.

[16] XING, P., DARVELL, L.I., JONES, J.M., MA, L., POURKASHANIAN, M., WILLIAMS, A., Fuel, 183, 2016, p. 39. 